EPiC Series in Engineering
Volume 3, 2018, Pages 1070-1077
HIC 2018. 13th International
Conference on Hydroinformatics

\title{
Scaling Characteristics of Storm-centered ARF Using Radar Rainfall
}

\author{
Eunji Kim ${ }^{1 *}$ and Boosik Kang ${ }^{1 \dagger}$ \\ ${ }^{1}$ Dankook University \\ eunjikimedankook.ac.kr, bskang@dankook.ac.kr
}

\begin{abstract}
In the hydraulic design practices, it is necessary to apply areal reduction factor to convert the point rainfall into the areal rainfall in the reference area. The fixed-area ARF (ARFf), which is commonly used, can be considered unrealistic because it is estimated through independent frequency analysis of the point rainfall and the areal rainfall. In this study, storm-centred ARF (ARFs) was estimated using radar rainfall data to reflect the spatial distribution characteristics of storm events effectively. ARFs representing the duration and the return period was extracted by $95 \%$ non-exceedance probability of the Weibull distribution to derive envelope covering all values from various storm events. ARFs has a correlation with not only the reference area but also the duration and the return period. Their relationships are defined as the scaling factors. A new ARFs equation that reflects the spatio-temporal characteristics of actual rainfall is presented.
\end{abstract}

\section{Introduction}

Design for the hydraulic structures, the areal reduction factor (ARF) is used to convert the point probability rainfall into the areal probability rainfall within the reference area. The rainfall intensity is the largest in the center of the storm event and decreases with the distance from the center. ARF reflects these spatial distribution characteristics of storm event.

In previous studies, ARF was estimated primarily using gauge rainfall data and applying fixed-area method (ARFf), which is by an independent frequency analysis of point rainfall and areal rainfall. Generally, ARFf is estimated by the ratio of point probability rainfall and areal probability rainfall (USWB, 1958). In the UK, ARFf is averaged the ratio of annual maximum point rainfall and areal rainfall (NERC, 1975). In South Korea, ARFf is applied to estimate the areal probability rainfall for design flood discharge (MLTM, 2011). However, ARFf is not considered that the storm event occurred at the same time, as it is estimated by an independent frequency analysis of annual maximum point rainfall and areal rainfall. ARFf differs from the values from the actual storm event because the spatial

\footnotetext{
* Masterminded EasyChair and created the first stable version of this document

${ }^{\dagger}$ Created the first draft of this document
} 
distribution of rainfall is not reflected when the density of gauge rainfall station is low. Meanwhile, the storm-centered ARF (ARFs) is the method that estimating by maximum value of synchronized, assuming the center of the storm event is located at the center of the reference area. Estimating ARFs, it is easy to identify the spatial structure of rainfall. In the absence of radar observation systems, gauge rainfall data were used to estimate ARFs (Desbordes et al.,1984; Asquith and Famiglietti, 1999). After the analysis of high-resolution radar images became possible, many researches have been active on estimating ARFs using radar rainfall data (Bacchi and Ranzi, 1996; Durrans et al., (2002); Olivera et al., 2008; Martins et al., 2014; Wright et al., 2014).

In this study, ARFs was estimated using radar rainfall data, which could effectively reflect the spatial distribution characteristics of synchronized storm event. Due to the characteristics of ARFs estimation method, the values estimated from the various storm events were scattered, so ARFs representing the specific duration and return period, was extracted as $95 \%$ non-exceedance probability of Weibull distribution. Extracted values are correlated not only to the reference area but also to the duration and the return period, expressed as scaling factors. Using them, a new equation is proposed to estimate ARFs reflecting the spatial and temporal characteristics.

\section{Data}

Weather radar is a remote sensing equipment that measures and predicts the atmospheric phenomena through clouds and rainfall. It also used to identify rainfall events and their internal structures (Doviak, 1993; Bringi and Chandrasekar, 2001). However, quantitative estimation of rainfall using weather radar is not simple. So the quality control (QC) is carried out to improve the accuracy of rainfall estimation (Smith et al., 1999; Seo and Breidenbach, 1999; Krajewski and Smith, 2002).

The Korea Meteorological Administration (KMA) has operated 11 single-polarity weather radars nationwide. The data produced at each station provides information in limited area, making it difficult to understand the weather condition in large area. So KMA provides the composite radar images every 10 minutes. In this study, the composite radar images of KMA used and ARFs estimated by storm events in the flood season (June to September) during 2007 to 2012.

\section{Methodology}

\subsection{Storm-centered ARF}

ARFs based on the radar rainfall data is estimated as the ratio of the areal rainfall to point rainfall of the same event. Figure 1 shows the process of the ARFs estimation using radar data.

Generally, the maximum rainfall intensity occurs at the storm center, so the coordinates of the grid where the maximum rainfall occurs are selected as the center of a storm event (Fig. 2). Since it is highly uncertain to assume that the value of the single grid as the central rainfall, so the average value of the central grid and the 8 surrounding grids was determined to the central rainfall value, and it can be considered as the point rainfall of ARFs. To estimate the areal rainfall, the area considering the shape and direction angle of storm was determined as circle or ellipse. In the case of elliptical shape, the directional angle was determined by comparing the skewness in 5 degrees. The ratio of major axis and minor axis of the ellipse is determined from the ratio of 1:1(circular) to 1:15(ellipse) (Fig. 3). The optimal ratio is the ratio when the areal rainfall of $1,250 \mathrm{~km} 2$ is the maximum.

ARFs is estimated by dividing the areal average rainfall by the point rainfall, and it can be express as shown in Eq. (1). 
$A R F_{A}=\frac{\frac{1}{A} \int_{A} R_{P} d A}{R_{P 0}}$

Where $\mathrm{A}$ is the area of rainfall $\left(\mathrm{km}^{2}\right), \mathrm{ARF}_{\mathrm{A}}$ is the $\mathrm{ARF}$ of area $\mathrm{A}, \mathrm{R}_{\mathrm{P}}$ is the areal rainfall $(\mathrm{mm})$, and $\mathrm{R}_{\mathrm{P} 0}$ is the point rainfall (mm).
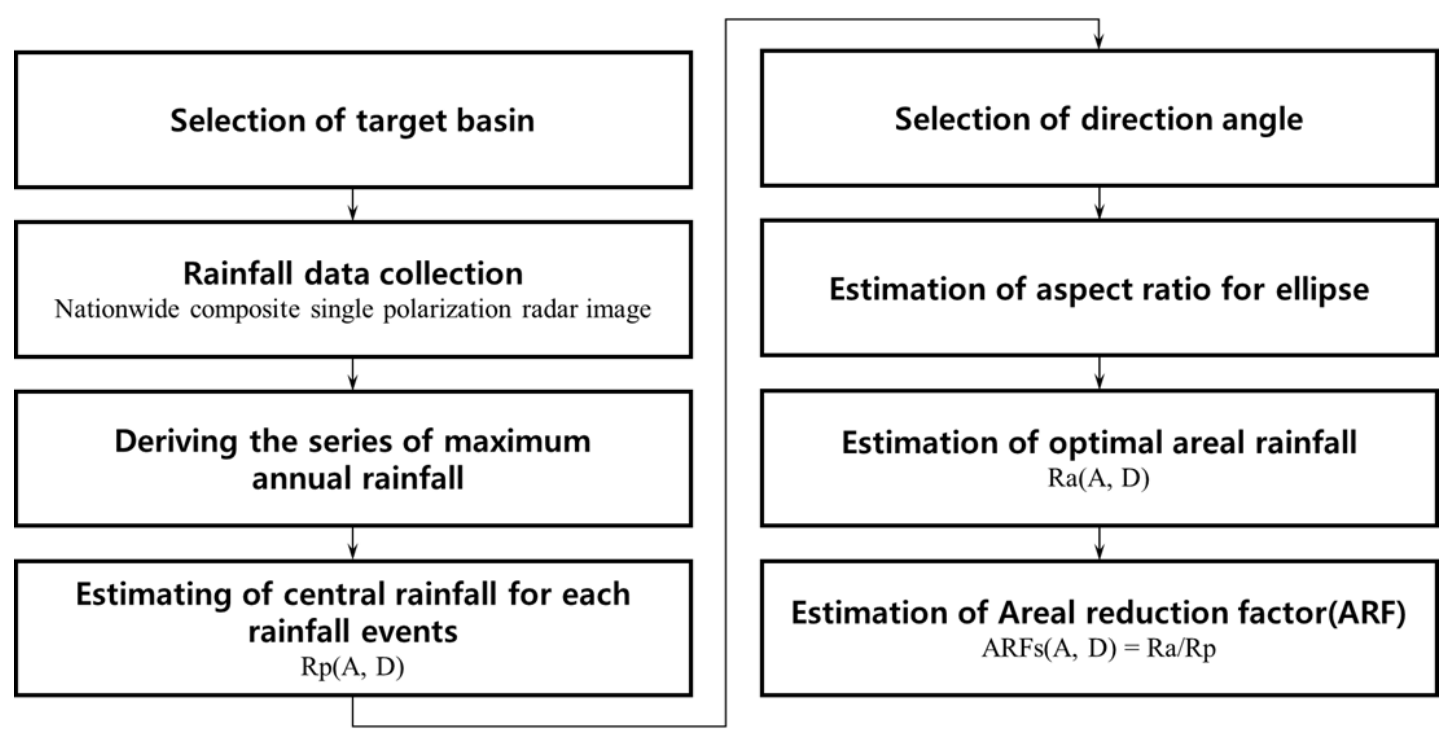

Figure 1: Schematic diagram of ARFs estimation using radar data

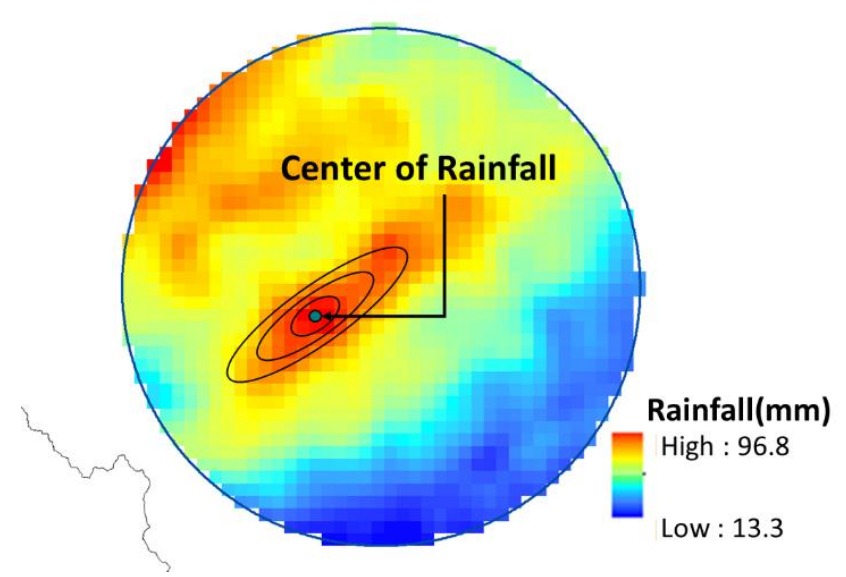

Figure 2: Conceptual diagram of the storm center using radar image 


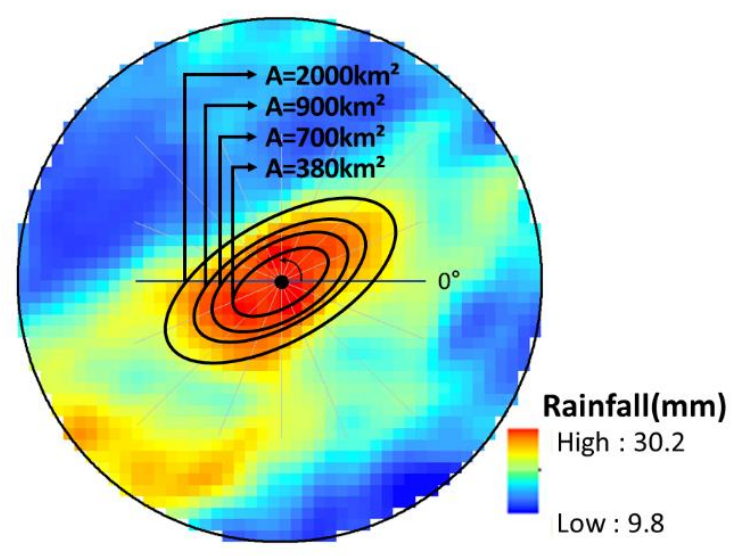

Figure 3: Conceptual diagram of the areal rainfall estimation using radar image (elliptical shape)

\subsection{Storm-centered ARF}

ARFs is estimated as the ratio of the maximum point rainfall to the maximum areal average rainfall of the storm event, so the frequency is not considered. However, it is required to estimate ARF for the return period because the hydrological design frequency is preferentially selected during design flood estimation process of South Korea. As Table 1, the return period of ARFs is classified by the probability rainfall based on [3] using point rainfall of each event.

As values of ARFs are estimated by each storm events, they are scattered by duration and return period. Since the ARFs curve should be in the form of an envelope covering all values, so the probability distribution is applied to select representative ARFs. The modified Weibull distribution is applied to reflect the characteristics of the ARF with the upper limit of 1 and $95 \%$ non-exceedance probability is determined as the representative value.

\begin{tabular}{c|ccccc|c}
\hline \multirow{2}{*}{$\begin{array}{c}\text { Duration } \\
\text { (hour) }\end{array}$} & $0-10$ & $10-20$ & $20-50$ & $50-80$ & $80-100$ & Sub total \\
\cline { 2 - 7 } & 251 & 174 & 120 & 21 & - & 566 \\
3 & 153 & 105 & 57 & 13 & 3 & 331 \\
6 & 63 & 58 & 36 & 12 & 7 & 176 \\
12 & 27 & 37 & 24 & 26 & 17 & 131 \\
24 & 29 & 23 & 29 & 24 & 11 & 116 \\
\hline Sub total & 523 & 397 & 266 & 96 & 38 & 1320 \\
\hline
\end{tabular}

Table 1: Classification of storm events by return period and duration (flood season of 2007 to 2012)

\section{Result}

\subsection{ARF curveStorm-centered ARF}

ARFs curve based on the radar data is plotted by the duration $(1,3,6,12$, and 24 hours) and the return period $(0-10,10-20,20-50,50-80$, and 80-100 years). The regression of the ARFs curve is applied 
the exponential fitting equation [16] which is same as the ARFf curve of South Korea [3]. It is shown in Eq. (2).

$A R F(A)=1-M \exp \left[-\left(a A^{b}\right)^{-1}\right]$

where $\mathrm{A}$ is the reference area $(\mathrm{km} 2), \mathrm{M}, \mathrm{a}$, and $\mathrm{b}$ is regression constants.

ARF curves show the relationship between the ARF and the reference area, and the reduction characteristics differ depending on the duration and the return period (Fig. 4). The relationship between ARFs of the reference area $1,250 \mathrm{~km} 2$ and the return period is given in Figure 5, and the relationship with the duration is given in Figure 6. ARFs tends to decrease with the return period. In other words, the larger the heavy storm scale, the lower values (Fig. 5). In Figure 6, ARFs increases with the duration and the reduction of 24 hours duration is very small.

These characteristics of ARFs differ with the reference area. The difference was compared using ARFs of 3 hours duration (return period-ARFs) and 10-20 years of return period (duration-ARFs). To compare Figure 5 and Figure 7, the scale characteristics are more apparent in the reference area. Figure 7 shows that the larger the reference area, the greater the decrease in ARFs for storm scales. These scale characteristics are also clearly visible in Figure 8, where the larger the reference area, the greater the rate of increase in ARFs with the duration. In this regard, parameterizing these scale characteristics helps to derive ARF relationship equation more effectively.

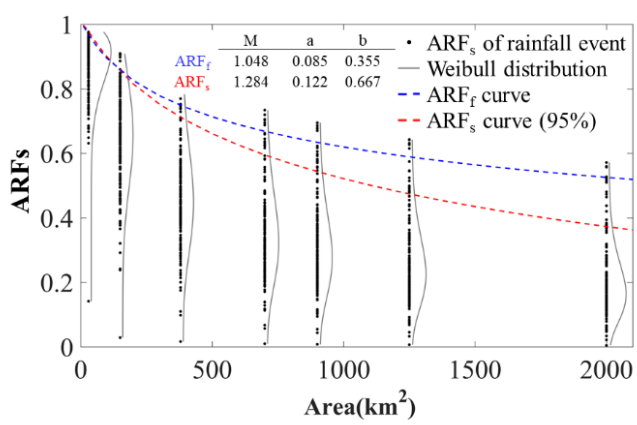

(a) $\mathrm{D}=1 \mathrm{hr}, \mathrm{T}=10-20 \mathrm{yr}$

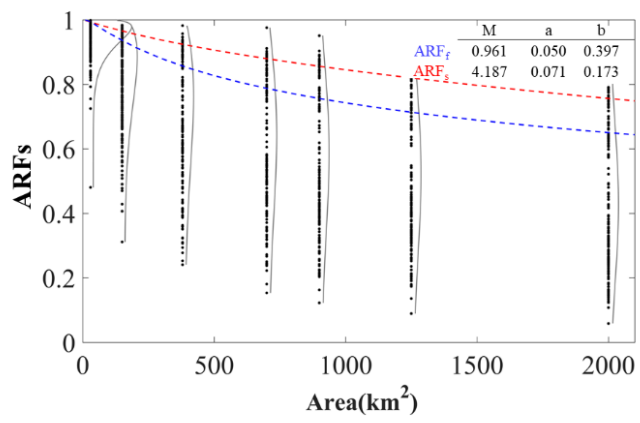

(c) $\mathrm{D}=3 \mathrm{hr}, \mathrm{T}=10-20 \mathrm{yr}$

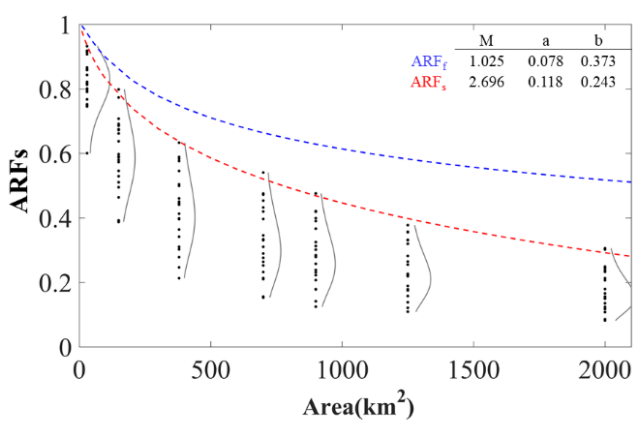

(b) $\mathrm{D}=1 \mathrm{hr}, \mathrm{T}=50-80 \mathrm{yr}$

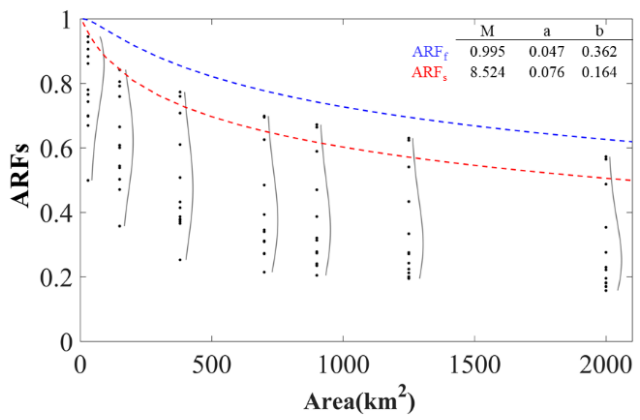

(d) $\mathrm{D}=3 \mathrm{hr}, \mathrm{T}=50-80 \mathrm{yr}$

Figure 4: ARF curves by duration and return period

\subsection{Scaling factor of ARFs}

It is already known that ARF increases with duration in many studies (NERC, 1975; Stuwart, 1989; Durrans et al., 2002; Olivera et al., 2008; Allen and DeGaetano, 2005a]. ARFs estimated in this study also showed the same result. As shown in Figure 8, ARFs had spatio-temporal scale characteristics. The slope of the semi-log plot for ARFs and duration is defined as scaling factor $\theta$. It is increased with the reference area, and the slope between the two indices increased with the return period (Fig. 9). The 
slope of $\theta$ based on the reference area is defined as another scaling factor $\alpha$ and the relationship with the duration to the return period is shown in Figure 10. Also, the slope of the return period and $\alpha$ is defined as $\beta$. In this case, the scaling factors of 80-100 years of return period are excluded from the compassion because there are no storm events included in that section (Table 1).

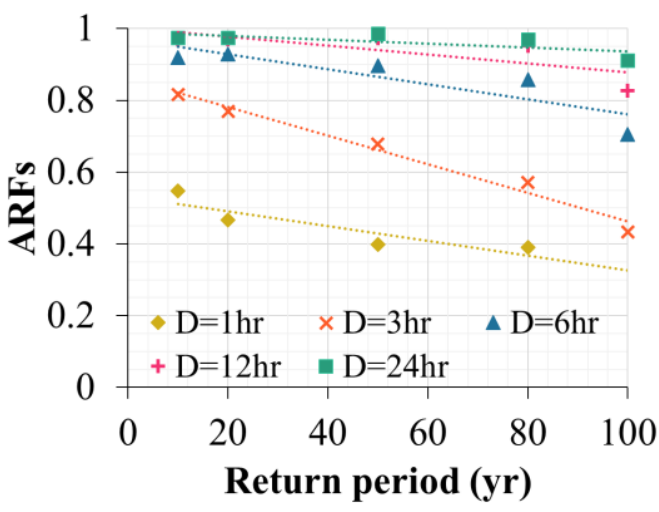

Figure 5: ARFs due to return period by each duration $\left(\mathrm{A}=1250 \mathrm{~km}^{2}\right)$

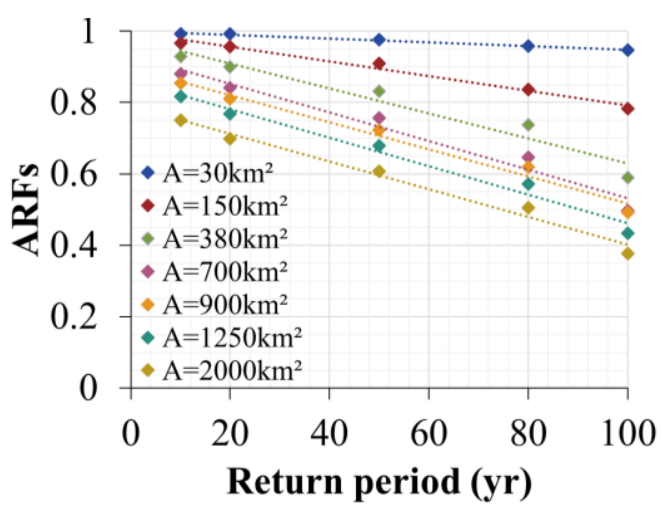

Figure 7: ARFs due to return period by each reference area $(\mathrm{D}=3$ hours)

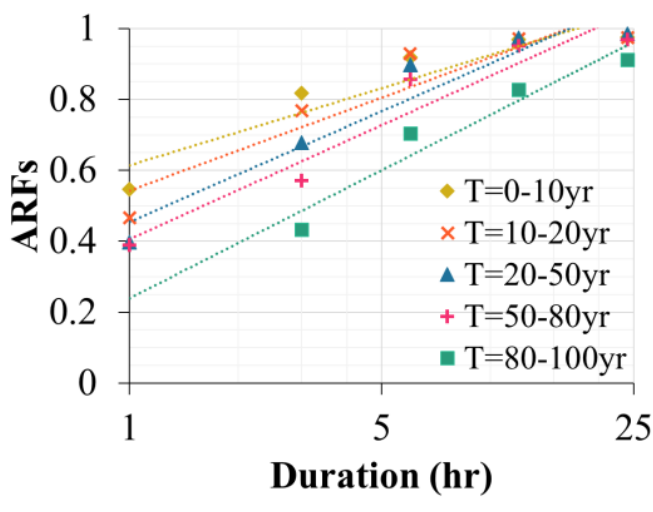

Figure 6: ARFs due to duration by each return period $\left(A=1250 \mathrm{~km}_{2}\right)$

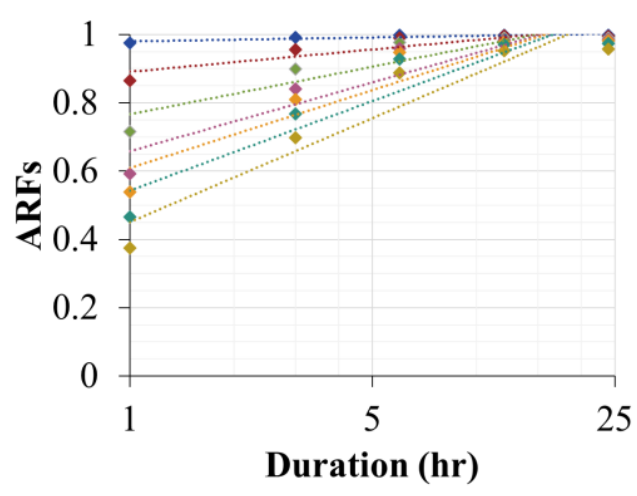

Figure 8: ARFs due to duration by each reference area $(\mathrm{T}=10-20$ years)

\subsection{ARFs equation}

Scaling factors $\theta, \alpha$ and $\beta$ were defined as coefficient representing the spatio-temporal scale characteristics of ARFs. Using them, we propose a new ARF equation to reflect the spatio-temporal characteristics of storm events.

ARF can be defined as the equation for the duration using $\theta$ defined in Figure 8, which shows the relationship between duration (D) and ARFs by reference area. It is shown in Eq. (3). In Figure 9, $\theta$ can be represented using the reference area and $\alpha$ like Eq. (4). In the same way, $\alpha$ can be expressed as Eq. (5) using return period $(\mathrm{T})$ and $\beta$.

$A R F=\theta \ln D+C_{1}$

$\theta=\alpha \ln A+C_{2}$

$\alpha=\beta \ln T+C_{3}$

Where $\mathrm{C}_{1}, \mathrm{C}_{2}$, and $\mathrm{C}_{3}$ are constants. Combining Eq. (3-5), ARF is expressed by Eq. (6). 
$A R F=\beta(\ln A)(\ln D)(\ln T)+C$

Where $\beta$ is the scaling factor of 0.0008 (Fig. 10), and $\mathrm{C}$ is a constant that varies with the reference area and duration.

The exponential equation using in South Korea is expressed only for the reference area and the regression constants for ARFf were proposed by duration and return period derived from the frequency analysis (MLTM, 2011). However, ARFs estimated in this study reflects the spatio-temporal characteristics of storm events, so it is not appropriate to apply the same equation of ARFf. Therefore, we defined the scaling factors to parameterize two or more spatio-temporal factors and derived a new equation for the reference area, duration and return period.

The equation reflects spatio-temporal scale characteristics of ARFs and actual rainfall. However, it was difficult to obtain various frequency of rainfall events because of the short period of the radar data (6 years). Especially, as the frequency is low, the number of the rainfall events considered was very small. In future studies, more reliable ARFs and scaling factor will be obtained by adding more storm events of radar data.

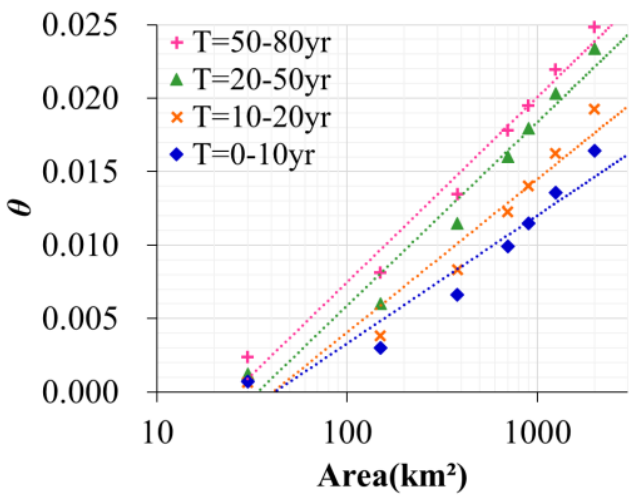

Figure 9: Scaling factor $(\theta)$ for reference area

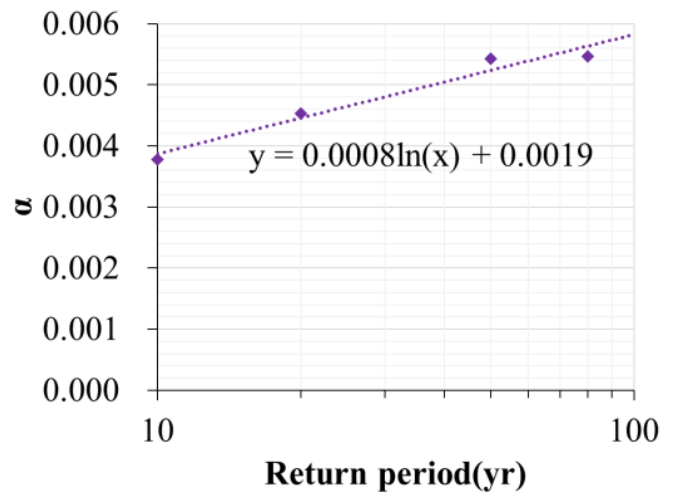

Figure 10: Scaling factor $(\alpha)$ for return period

\section{Conclusion}

\subsection{ARF curveStorm-centered ARF}

To improve the limitation of the fixed-area ARF that has been used in South Korea, we estimated the storm-centered ARF. Using radar data is effective in estimating ARFs and it reflects the spatiotemporal scale characteristics of storm events. Also, a new ARF equation was proposed using not only the reference area but also the duration and the return period. The result of this study can be summarized as follows.

- Radar rainfall data was used to determine the shape and grasp internal structure of the storm. Since the values of ARFs is calculated differently according to the various storm events, the Weibull distribution is applied to select a representative value of the specific duration and return period.

- ARFs decrease with the return period, which means that the larger the storm, the lower ARFs. In addition, ARFs increases with the duration, and when the specific duration is exceeded, the areal reduction property is hardly achieved. 
- The relationship between ARFs and the temporal characteristics was more apparent in relationship with the reference area. The larger the reference area, the greater the decreasing rate of ARFs, and the greater the increasing rate of ARFs for duration.

- Since ARFs has scale characteristics, it is not appropriate to represent ARFs curve regression equation expressed only as the reference area. More than two characteristics of ARFs are parameterized into the scaling factors and they compose ARFs regression equation.

\section{References}

Allen, Robert J., and Arthur T. DeGaetano. "Areal reduction factors for two eastern United States regions with high rain-gauge density." Journal of Hydrologic Engineering 10.4 (2005): 327-335.

Asquith, W. H., and J. S. Famiglietti. "Precipitation areal-reduction factor estimation using an annualmaxima centered approach." Journal of Hydrology 230.1-2 (2000): 55-69.

Bacchi, Baldassare, and Roberto Ranzi. "On the derivation of the areal reduction factor of storms." Atmospheric Research 42.1-4 (1996): 123-135.

Bringi, V. N, and V. Chandrasekar. Polarimetric Doppler weather radar: principles and applications. Cambridge university press, 2001.

Desbordes, M., P. Raous, and Y. Trévisiol. "Areal reduction factors on short time and space intervals." Water Science and Technology 16.8-9 (1984): 189-198.

Doviak, Richard J. Doppler radar and weather observations. Courier Corporation, 1993.

Durrans, S. Rocky, Lesley T. Julian, and Michael Yekta. "Estimation of depth-area relationships using radar-rainfall data." Journal of hydrologic Engineering 7.5 (2002): 356-367.

Krajewski, W. F., and J. A. Smith. "Radar hydrology: rainfall estimation." Advances in water resources 25.8-12 (2002): 1387-1394.

Lee, K. A study on the regional frequency analysis of the point rainfall: applied in the Han river basin, Yonsei University, 1984 (Korean).

Martins, J. R. S., L. S. Girnius, and M. G. M. Pinto. "Point to area rainfall relationships using radar data." São Paulo (2014).

MLTM. Study on improvement and supplement of Probability Rainfall in South Korea. Ministry of Land, Transport and Maritime Affairs, 2011 (Korean).

NERC. Flood studies report, Volume II . Natural Environment Reseach Council : London, UK, 1975

Olivera, F., Choi, J., Kim, D., and M. H. Li. "Estimation of average rainfall areal reduction factors in Texas using NEXRAD data." Journal of Hydrologic Engineering 13.6 (2008): 438-448.

Seo, D-J., J. P. Breidenbach, and E. R. Johnson. "Real-time estimation of mean field bias in radar rainfall data." Journal of Hydrology 223.3-4 (1999): 131-147.

Steiner, Matthias, et al. "Effect of bias adjustment and rain gauge data quality control on radar rainfall estimation." Water Resources Research 35.8 (1999): 2487-2503.

Stewart, E. J. "Areal reduction factors for design storm construction: Joint use of raingauge and radar data." Association of Hydrological Sciences 181 (1989): 31-40.

U.S. Weather Bureau. Rainfall Intensity-Frequency Regime 2. Southeastrn United States Tech. Paper 29. U.S. Department of Commerce, 1958.

Wright, Daniel B., James A. Smith, and Mary Lynn Baeck. "Critical examination of area reduction factors." Journal of Hydrologic Engineering 19.4 (2014): 769-776. 